\title{
Estrutura populacional, razão sexual e abundância de Podocnemis sextuberculata (Testudines, Podocnemididae) na Reserva de Desenvolvimento Sustentável Mamirauá, Amazonas, Brasil
}

\author{
Augusto Fachín-Terán ${ }^{1,2}$, Richard C. Vogt ${ }^{3}$, John B. Thorbjarnarson ${ }^{4}$ \\ 1 Universidade do Estado do Amazonas. Escola Normal Superior. Avenida Darcy Vargas S/N. Bairro Chapada. 69050- \\ 020, Manaus, Amazonas, Brasil. E-mail: fachinteran@yahoo.com.br. \\ 2 Universidad Nacional de la Amazonia Peruana. Departamento Académico de Ecología y Manejo. Facultad de Ciencias \\ Biológicas. Casilla Postal 496. Iquitos, Loreto-Perú. \\ 3 Instituto Nacional de Pesquisas da Amazônia - INPA. Coordenação de Pesquisa em Biologia de Água Doce, Alameda \\ Cosme Ferreira 1756, Aleixo, C.P. 478, 69011-970, Manaus, AM, Brasil. E-mail: vogt@inpa.gov.br ou \\ dickturtle@aol.com. \\ ${ }^{4}$ Wildlife Conservation Society. E-mail: jthorbjarnarson@wcs.org.
}

\begin{abstract}
Population structure, sex ratio and abundance of Podocnemis sextuberculata (Testudines, Podocnemididae) in the Reserva de Desenvolvimento Sustentável Mamirauá, Amazonas, Brazil. We studied turtles in the focal area of the Reserva de Desenvolvimento Sustentável Mamirauá from September 1996 through August 1998. The reserve is located in the western part of the Brazilian Amazon, between the Japurá, Solimões, and Auti-Paraná rivers, near the city of Tefé, in the state of Amazonas. In this study the populacion structure, sex ratio and abundance of Podocnemis sextuberculata were investigated. We intensively studied the population of turtles in the Jarauá river basin in order to determine population structure. We sampled turtles in different sectors of the focal area of the reserve for one month each year during July and August 1997 and 1998. We captured the turtles using flag gill nets and trammel nets. The type of net and size of the nets used influenced the size of the turtles captured. The nets used by the local fishermen were sexually selective in the capture of turtles. Seventy two per cent of the P. sextuberculata captured were adults; $13 \%$ juveniles and $14.7 \%$ subadults. During the second year of the study we found a lower density of turtles in the five areas which we sampled both years. The sex ratio of captured $P$. sextuberculata was 1.87 males per female.
\end{abstract}

Keywords: Testudines, Podocnemididae, Podocnemis sextuberculata, population structure, sex ratio, abundance, Amazonia, Brazil.

Palavras-chave: Testudines, Podocnemididae, Podocnemis sextuberculata, estrutura populacional, razão sexual, abundância, Amazonas, Brasil.

Recebido em 27 de março de 2003

Aceito em 10 de junho de 2003

Distribuído em 31 de outubro de 2003 


\section{Introdução}

Nosso conhecimento da ecologia populacional de muitas espécies de quelônios de água doce permanece escasso (Bury, 1979). Isto é especialmente o caso de Podocnemis sextuberculata, uma das espécies de menor porte do gênero. Informações básicas sobre a historia natural desta espécie podem ser encontradas em Ernst e Barbour (1989), mas pouco se conhece sobre sua biologia populacional e ecologia. As escassas informações disponíveis referem-se principalmente a aspectos reprodutivos (Vanzolini 1977, Vanzolini e Gomes 1979, Soini 1995a, b, Soini e Coppula 1995, Soini e Soini 1995a, b, Pezzuti 1998) e, com menor freqüência, à dieta (Almeida et al. 1986, Fachín-Terán et al. 1995), criação em cativeiro (Fachín-Terán et al. 1992) e uso na alimentação humana (Fachín-Terán et al. 2000).

$\mathrm{O}$ único trabalho sobre a biologia geral de uma espécie de Podocnemis em áreas naturais foi feito por Ramo (1982), na Venezuela, com $P$. vogli, incluindo, entre outros aspectos, a estrutura da população. No entanto, a maioria das espécies de quelônios amazônicos ainda está para ser pesquisada e vem sendo explorada de maneira não sustentável, principalmente as do gênero Podocnemis.

Declínios populacionais de quelônios em muitas partes da América do Sul, principalmente do gênero Podocnemis (Smith 1979, Johns 1987, Ojasti 1995, Soini 1997a, b), levaram os governos de diferentes países do continente a implementar programas de conservação. Entre as principais medidas de manejo, estão a proteção dos locais de desova e o translocamento de ninhos para locais protegidos (Cantarelli e Herde 1989, Soini 1997a). Essas ações vêm sendo realizadas durante mais de duas décadas, sem contudo serem acompanhadas por avaliações dos efeitos desses programas na razão sexual, na densidade e na estrutura das populações. No Brasil, esses programas não protegem qualquer tabuleiro na parte média do rio Solimões.

As espécies que mereceram maior atenção dos programas de conservação foram Podocnemis expansa, $P$. unifilis e $P$. sextuberculata. Nas três espécies, a temperatura de incubação determina o sexo dos filhotes (Alho et al. 1984, Souza e Vogt 1994, Páez 1995, Pezzuti 1998). Isso significa que, nos locais onde se executam esses programas, a razão sexual foi provavelmente desviada para um determinado sexo. Experimentos de manipulação de ninhos em tartarugas marinhas mostraram o perigo de masculinizar a população em espécies com determinação sexual dependente da temperatura (Mrosovsky 1982, Vogt 1994).

Podocnemis sextuberculata é considerada espécie ameaçada pela IUCN. Os critérios utilizados para classificá-la nessa categoria foram a diminuição das populações, independentemente da qualidade do hábitat, e os níveis atuais e potenciais de exploração (IUCN 1996). Entretanto, não existem dados quantitativos que sustentem esses critérios em nenhum dos países onde a espécie ocorre.

Na Reserva de Desenvolvimento Sustentável Mamirauá (RDSM), a população de $P$. sextuberculata vem sendo permanentemente explorada pelo homem, o que potencialmente pode causar profundas modificações na densidade, estrutura populacional e na razão sexual. Informações sobre esses parâmetros são indispensáveis quando se trata de uma espécie suscetível de manejo, como é o caso de P. sextuberculata. A carência de dados populacionais dificulta a determinação de sua situação atual e a implantação de práticas de manejo e conservação da espécie nessa área da região amazônica.

Neste estudo foram investigados (1) a seletividade dos aparelhos de captura, (2) a estrutura populacional, (3) a razão sexual e (4) a abundância relativa de $P$. sextuberculata.

\section{Materiais e Métodos}

\section{Área de Estudo}

Este estudo foi realizado na Área Focal da RDSM. A reserva está localizada na Amazônia 
Ocidental Brasileira, entre os rios Japurá, Solimões e Auti-Paraná, perto da cidade de Tefé, no estado do Amazonas. Geograficamente, está localizada entre $03^{\circ} 08^{\prime} \mathrm{S}-64^{\circ} 45^{\prime} \mathrm{W}$ e $02^{\circ} 36^{\prime} \mathrm{S}$ - $67^{\circ} 13^{\prime} \mathrm{W}$, tem uma extensão de 1.124.000 ha e está dividida em uma Área Subsidiária e uma Área Focal. É a primeira Reserva de Desenvolvimento Sustentável criada no Brasil (1996), e a única Unidade de Conservação inteiramente localizada em florestas inundáveis de várzea. Seu objetivo é a conservação, investigação e manejo da biodiversidade com participação da população local (SCM 1996).

\section{Amostragem}

As amostragens foram realizadas entre setembro de 1996 e agosto de 1998 na Área Focal da RDSM. Redes malhadeiras foram usadas intensivamente na captura até a primeira quinzena de julho de 1997. A partir desta data, foram usadas redes transmalhas (Trammel Nets).

Para amostrar diferentes setores da reserva, foram feitas duas viagens (uma vez por ano) de um mês de duração em torno da Área Focal. As viagens foram realizadas no início da seca, nos meses de julho e agosto de 1997 e 1998, quando o nível da água na cidade de Tefé atingiu a cota de 12,6 e 11,6 m, respectivamente. Uma amostragem mais intensiva foi realizada no Sistema Hidrológico do Paraná do Jarauá, situado no setor Jarauá da reserva (Figura 1).

\section{Métodos de Captura}

Os animais foram capturados com dois tipos de redes: malhadeiras e transmalhas. As malhadeiras tinham comprimento que variava entre 100 e $150 \mathrm{~m}$ e uma profundidade de $3 \mathrm{~m}$, com uma linha de flutuadores na parte superior, sem chumbo na parte inferior, e cujos diâmetros de malha esticada foram de 12,16 e 20 $\mathrm{cm}$. Quando havia maior correnteza no canal, foram usadas pilhas de tamanho grande, as quais foram atadas na parte inferior, com a finalida- de de que a malhadeira tocasse o fundo. A transmalha teve um comprimento de 100 a 150 m e foi constituída de três malhas, as duas laterais grandes, de 60, 68 e $92 \mathrm{~cm}$ de malha esticada, e a do meio de 11,15 e $21 \mathrm{~cm}$, com uma profundidade de 3,5, 4,0 e 4,5 m. Na parte superior, eram unidas com uma corda de nylon com flutuadores; na parte inferior, apresentavam um cordel com chumbo, cuja função era a de fazer a rede tocar o fundo do canal.

As redes foram armadas em locais profundos no canal dos paranás, ressacas, lagos e nos remansos perto das praias, com a finalidade de descobrir onde ocorria cada classe de tamanho e sexo de $P$. sextuberculata. Essas redes foram colocadas transversalmente à margem dos corpos d'água, compreendendo geralmente todas as profundidades do canal. Nos remansos, as redes foram colocadas perpendicularmente à praia, seguindo a correnteza do rio.

As iaçás ( $P$. sextuberculata) caem nas redes malhadeiras com seu movimento natural, já que a malha atua como uma barreira que faz com que os animais, no seu intento de passar pelo local, fiquem presos na malha. Nas transmalhas, ficam presas na malha do meio, que forma uma espécie de saco quando acionada com as malhas laterais.

Uma vez capturados, os quelônios foram numerados com um marcador de tinta permanente na parte média do plastrão. Os animais foram logo levados à base flutuante da Estação Ecológica do Jarauá, onde foram pesados, medidos e sexados. Os juvenis foram marcados permanentemente mediante injeção com um microchip (PIT, Passive Integrated Transponder) na musculatura da parte dorsal da cauda. Os sub-adultos e adultos foram marcados com etiquetas plásticas numeradas (floy cinch up tags), presas à parte dorsal posterior direita por meio de dois orifícios na carapaça feitos com um furador nas placas marginais $9 \mathrm{e}$ 11 do lado direito. Para aumentar a segurança de uma identificação correta, cada animal foi marcado permanentemente com um corte de forma retangular no centro do escudo marginal 
Fachín-Terán et al.

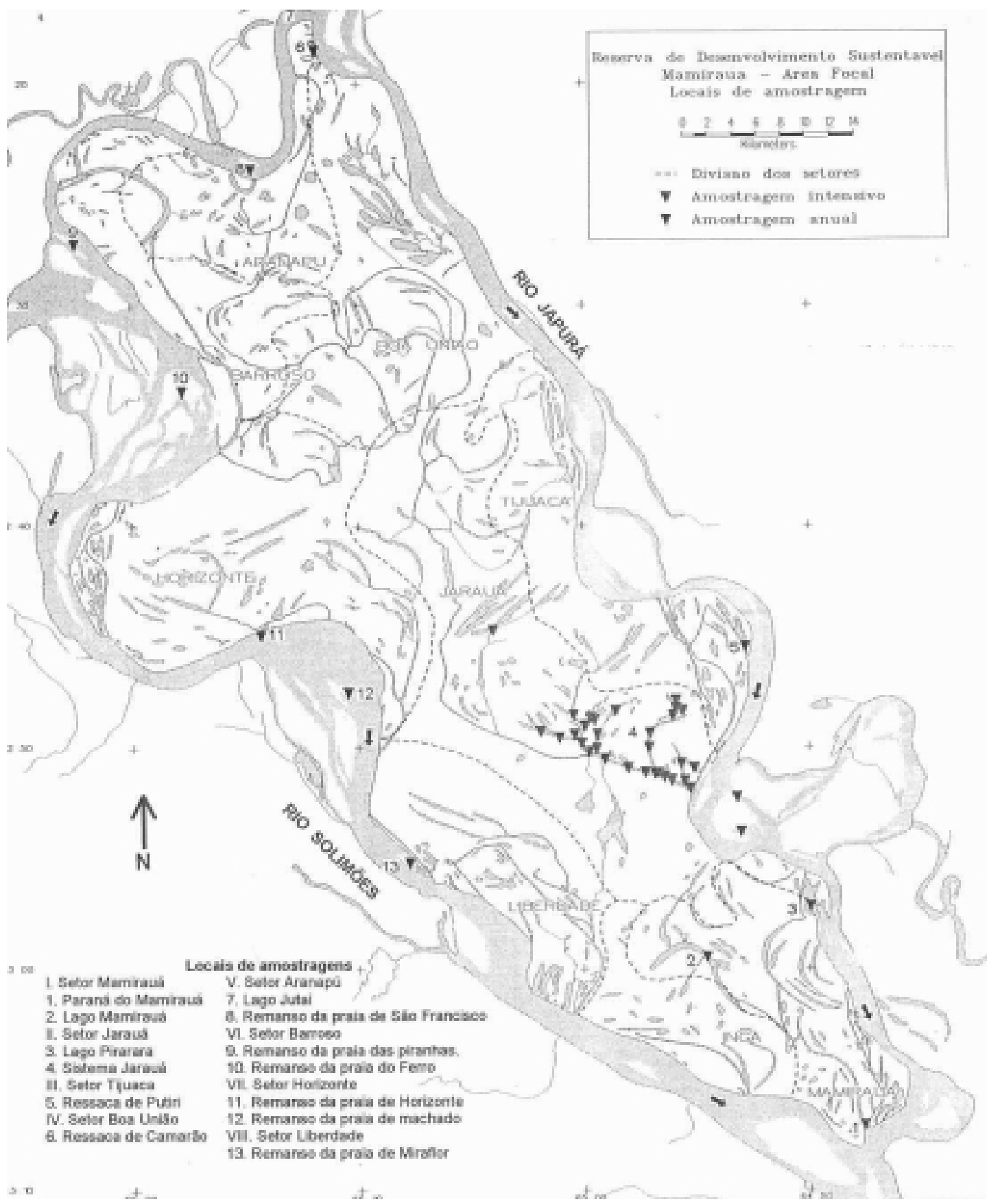

Figura 1 - Locais de amostragem de Podocnemis sextuberculata na Área Focal da RDSM, Amazonas, Brasil. 
da carapaça com um código previamente estabelecido (Cagle 1939). Logo após a tomada dos dados e marcações, os animais foram liberados no local de captura.

As capturas nos diferentes locais tiveram uma duração de 12 a 72 horas. Os locais de captura e recaptura foram registrados mediante o uso do Sistema de Posicionamento Global GPS.

\section{Considerações básicas sobre a classificação da idade, estrutura populacional, abundância relativa, razão sexual e índice de recaptura}

A característica principal que distingue $P$. sextuberculata de outras espécies de quelônios é a presença de seis tubérculos no plastrão, mais notória em animais recém-eclodidos e em fase juvenil. Com base na presença ou ausência de tubérculos, tamanho dos animais e exame do estado de maturidade das gônadas em animais mortos, consideramos juvenis os exemplares pequenos que apresentavam os tubérculos do plastrão bem desenvolvidos, subadultos aqueles de tamanho médio em que os tubérculos eram pequenos e estavam desaparecendo do plastrão e adultos aqueles indivíduos grandes e sem tubérculos.

Como se desconhece a idade em função do tamanho desta espécie em áreas naturais, estabelecemos arbitrariamente classes de tamanho com intervalos de $1 \mathrm{~cm}$ de comprimento da carapaça, usadas nas análises da estrutura populacional.

Segundo Gibbons (1990), a razão sexual funcional deve ser calculada com base nos indivíduos que alcançaram a maturidade. Neste estudo, foram considerados adultos os indivíduos sem tubérculos no plastrão.

Para o cálculo da densidade relativa, uma amostragem foi definida como a captura realizada durante o período de 48 horas. A taxa de captura (captura por unidade de esforço-CPUE) foi então calculada dividindo-se o número de indivíduos pelo número de horas de captura com redes.
O índice de recaptura, em ambos os sexos, foi calculado dividindo-se o número total de capturas pelo número de animais recapturados pela primeira vez. $\mathrm{O}$ resultado foi dividido por 100.

\section{Análises Estatísticas}

A diferença entre machos e fêmeas nos caracteres morfológicos foi comparada por meio de uma Análise de Variância (ANOVA). A seletividade dos aparelhos de captura foi testada por regressão múltipla. O tipo de malhadeira, o tamanho de malha e o sexo foram relacionados com o comprimento da carapaça, e as relações foram testadas com ANOVA. O teste de Qui-quadrado foi usado para comparar a proporção de sexos dos locais entre anos de amostragem. As análises estatísticas foram feitas no programa estatístico SYSTAT (Wilkinson 1990).

\section{Resultados}

\section{Número de Animais Capturados}

Durante todo o período de estudo, foram capturados 2458 indivíduos de $P$. sextuberculata: 1603 machos e 855 fêmeas. Destes, 87 indivíduos $(3,5 \%)$ foram recapturadas uma vez e três indivíduos $(0,1 \%)$, duas vezes (Tabela 1$)$. O maior número de capturas ocorreu durante a vazante no mês de agosto de 1997 e julho-agosto de 1998 nos remansos perto das praias de nidificação. A captura também foi alta durante a enchente no mês de dezembro de 1997 até fevereiro de 1998 nas ressacas e paranás, quando os animais estavam entrando do rio (Figura 2). $O$ índice de recaptura indica que machos têm $10 \%$ mais chance de serem recapturados.

\section{Hábitats}

As iaçás foram encontradas em diferentes tipos de hábitats, tendo sido capturadas principalmente nas ressacas $(38,2 \%)$, paranás $(31,2$ $\%)$ e remansos $(16,0 \%)$ (Tabela 2$)$. 
Tabela 1 - Número total de indivíduos de P. sextuberculata capturados e recapturados na Área Focal da RDSM.

\begin{tabular}{|c|c|c|c|c|c|c|}
\hline & \multicolumn{2}{|c|}{$\sigma^{x}$} & \multicolumn{2}{|c|}{ 우 } & \multicolumn{2}{|c|}{ TOTAL } \\
\hline & $\mathbf{N}$ & $\%$ & $\mathbf{N}$ & $\%$ & $\mathrm{~N}$ & $\%$ \\
\hline Captura sem retorno & 1552 & 96,8 & 816 & 95,4 & 2368 & 96,3 \\
\hline $1^{\mathrm{a}}$ Recaptura & 49 & 3,1 & 38 & 4,4 & 87 & 3,5 \\
\hline $2^{\mathrm{a}}$ Recaptura & 2 & 0,1 & 1 & 0,1 & 3 & 0,1 \\
\hline TOTAL & 1603 & 100 & 855 & 99,9 & 2458 & 99,9 \\
\hline
\end{tabular}

Tabela 2 - Número de indivíduos de P. sextuberculata capturados durante a enchente e a vazante em diferentes hábitats da Área Focal da RDSM.

\begin{tabular}{lcccccccccc}
\hline & \multicolumn{4}{c}{ ENCHENTE } & \multicolumn{1}{c}{ VAZANTE } & \multicolumn{3}{c}{ TOTAL } \\
\cline { 2 - 11 } HABITATS & $\sigma^{\top}$ & + & $\mathbf{N}$ & $\%$ & $\sigma^{\boldsymbol{x}}$ & \% & $\mathbf{N}$ & $\%$ & $\mathbf{N}$ & $\%$ \\
\hline Ressaca & 311 & 120 & 431 & 47,7 & 344 & 163 & 507 & 32,6 & 938 & 38,2 \\
Paraná & 228 & 194 & 422 & 46,7 & 183 & 163 & 346 & 22,3 & 768 & 31,2 \\
Remanso & 29 & 11 & 40 & 4,4 & 275 & 79 & 354 & 22,8 & 394 & 16,0 \\
Lago & 10 & 1 & 11 & 1,2 & 157 & 113 & 270 & 17,4 & 281 & 11,4 \\
Chavascal & 0 & 0 & 0 & 0 & 65 & 6 & 71 & 4,6 & 71 & 2,9 \\
Cano & 0 & 0 & 0 & 0 & 1 & 5 & 6 & 0,4 & 6 & 0,2 \\
\hline TOTAL & $\mathbf{5 7 8}$ & $\mathbf{3 2 6}$ & $\mathbf{9 0 4}$ & $\mathbf{1 0 0}$ & $\mathbf{1 0 2 5}$ & $\mathbf{5 2 9}$ & $\mathbf{1 5 5 4}$ & $\mathbf{1 0 0}$ & $\mathbf{2 4 5 8}$ & $\mathbf{1 0 0}$ \\
\hline
\end{tabular}

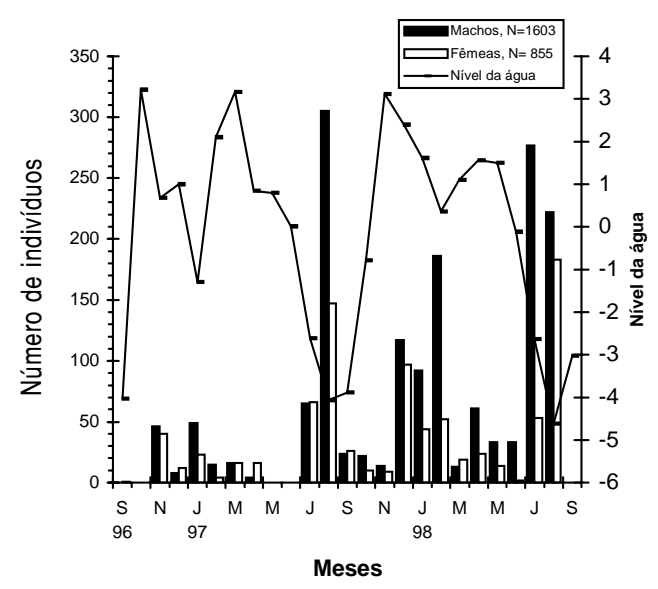

Figura 2 - Número de animais capturados durante os meses da amostragem na Área Focal da RDSM (barras) e variação do nível d'água (linha).

\section{Seletividade das Malhadeiras}

Os animais foram capturados principalmente com redes transmalhas (Tabela 3). O tipo de malhadeira e o tamanho das malhas influenciaram significativamente o tamanho dos animais capturados $(p=0,011$ e $p<0,001)$, mas não o sexo $(\mathrm{p}=0,064)$. Entretanto, o número de machos e fêmeas capturados nas malhadeiras evidencia uma captura seletiva em relação ao sexo.

\section{Mortalidade Durante a Captura}

Dos 2458 quelônios capturados, 62 $(2,52 \%)$ morreram nas malhadeiras (Tabela 4). Apesar de ser uma taxa relativamente baixa, demonstra como o uso de malhadeiras deve ser cuidadoso durante a pesquisa. Além 
Tabela 3 - Número de indivíduos de $P$. sextuberculata capturados segundo o tipo de rede e o tamanho da malha em função do sexo.

\begin{tabular}{|c|c|c|c|c|c|c|}
\hline & \multicolumn{3}{|c|}{ TRANSMALHA } & \multicolumn{3}{|c|}{ MALHADEIRA } \\
\hline & \multicolumn{6}{|c|}{ Tamanho das malhas $(\mathrm{cm})$} \\
\hline & 11 & 15 & 21 & 12 & 16 & 20 \\
\hline$\sigma^{x}$ & 168 & 1207 & 136 & 7 & 84 & 1 \\
\hline 우 & 161 & 410 & 257 & 11 & 10 & 6 \\
\hline SUBTOTAL & 329 & 1617 & 393 & 18 & 94 & 7 \\
\hline TOTAL & & 2339 & & & 119 & \\
\hline
\end{tabular}

Tabela 4 - Porcentagem de indivíduos de P. sextuberculata mortos por diferentes causas durante o período de estudo.

\begin{tabular}{|c|c|c|c|c|c|c|}
\hline \multirow{2}{*}{$\begin{array}{l}\text { CAUSAS DA } \\
\text { MORTE }\end{array}$} & \multicolumn{2}{|l|}{$\sigma^{x}$} & \multicolumn{2}{|c|}{ 우 } & \multicolumn{2}{|c|}{ TOTAL } \\
\hline & $\mathbf{N}$ & $\%$ & $\mathbf{N}$ & $\%$ & $\mathbf{N}$ & $\%$ \\
\hline Vivos & 1539 & 96,0 & 800 & 93,6 & 2339 & 95,16 \\
\hline Malhadeira & 36 & 2,2 & 26 & 3,0 & 62 & 2,52 \\
\hline Caça & 12 & 0,7 & 14 & 1,6 & 26 & 1,06 \\
\hline Piranhas $\left(^{\star}\right)$ & 9 & 0,6 & 4 & 0,5 & 13 & 0,53 \\
\hline No saco & 3 & 0,2 & 5 & 0,6 & 8 & 0,33 \\
\hline Candiru-açu (*) & 3 & 0,2 & 0 & 0 & 3 & 0,12 \\
\hline Boto $\left({ }^{*}\right)$ & 1 & 0,1 & 0 & 0 & 1 & 0,04 \\
\hline Pesquisa & 0 & 0 & 6 & 0,7 & 6 & 0,24 \\
\hline TOTAL & 1603 & 65,2 & 855 & 34,8 & 2458 & 100 \\
\hline VIVOS & 1539 & 96,0 & 800 & 93,6 & 2339 & 95,16 \\
\hline MORTOS & 64 & 4,0 & 55 & 6,4 & 119 & 4,84 \\
\hline
\end{tabular}

$\left(^{\star}\right)$ Atacaram as iaçás nas malhadeiras.

das redes terem sido revisadas periodicamente, de quatro em quatro horas, tempo determinado como o mais adequado, as mortes ocorreram principalmente quando a cabeça do animal ficava presa nas malhas, fazendo com que o fio pressionasse seu pescoço, dificultando o fluxo sangüíneo. Portanto, as mortes não ocorreram por afogamento, e a redução do tempo de visita às malhadeiras não reduzirá necessariamente a mortalidade.

Piranhas Serrasalmus sp. (0,53\%), candirus-açus Cetopsis coecutiens $(0,12 \%) \mathrm{e}$ botos Inia geoffrensis $(0,04 \%)$ foram predadores oportunistas, aproveitando-se do fato de as iaçás encontrarem-se presas na malhadeira, sem possibilidade de fuga. 


\section{Estrutura da População da Área Focal da RDSM}

O tamanho dos indivíduos (comprimento da carapaça) de $P$. sextuberculata da população em torno da Área Focal e da área amostrada no Sistema Hidrológico do Jarauá apresentou distribuição normal para os machos, com tamanhos mais freqüentes entre 17 e $22 \mathrm{~cm}$. Para as fêmeas, a tendência foi de uma curva bimodal (Figura 3). Recém-nascidos e juvenis menores de $7 \mathrm{~cm}$ de comprimento não estão representados porque não foram capturados.

Setenta e dois por cento dos indivíduos capturados foram animais adultos. Os juvenis e subadultos foram representados em proporções similares de 13 e 14,7\%, respectivamente. Em relação às faixas etárias por sexo, observou-se uma elevada porcentagem de machos adultos (90,5 \%). Fêmeas juvenis, subadultos e adultos foram bem representadas, sendo maior o número de fêmeas adultas (Tabela 5).

Houve diferença significativa de tamanho entre machos e fêmeas. Os machos foram significativamente menores que as fêmeas (Tabela 6). Machos juvenis, subadultos e adultos foram, em média, menores que as fêmeas (Tabela 7).

\section{Estrutura da População na Área Focal, Segundo as Classes de Tamanho e Locais de Amostragem}

Na Ressaca de Putiri, em 1997, foi observado um maior número de machos que de fêmeas, aparecendo poucos indivíduos pequenos de ambos sexos, tendo sido maior a captura de fêmeas subadultas e machos adultos, com poucas fêmeas grandes. Em 1998, a estrutura da população foi drasticamente modificada, não havendo a tendência de uma curva normal observada em 1997 para a população de machos. Os machos subadultos não foram encontrados, e o número de animais capturados foi menor (Figura 4A).

$\mathrm{Na}$ Ressaca de Camarão, durante a captura realizada em 1997, houve um maior número de fêmeas que de machos, com indivíduos acima de $15 \mathrm{~cm}$ de comprimento. A tendência da distribuição de freqüências dos tamanhos das fêmeas foi de uma curva normal. Em 1998, a distribuição de freqüências mudou radicalmente. Poucos indivíduos foram capturados, encontrando-se somente juvenis com menos de $13 \mathrm{~cm}$ de comprimento (Figura 4B).

Em 1997, no Lago Jutai, apesar das iaçás serem capturadas por pescadores profissionais, coletamos um elevado número de indivíduos, aparecendo os machos $(\mathrm{N}=72)$ em maior número que as fêmeas $(\mathrm{N}=45)$. A distribuição de freqüências dos tamanhos dos machos mostrou a forma de uma curva normal e a das fêmeas não apresentou nenhum padrão definido. Essa situação modificou-se completamente em 1998, com uma grande diminuição de indivíduos em todas as classes de tamanho; fêmeas juvenis e subadultos não foram encontrados (Figura 4C). Nesse lago, encontramos comunitários da comunidade Pentecostal capturando iaçás com uma rede malhadeira de nylon de aproximadamente 500 metros.

O elevado número de machos e fêmeas adultas capturados no remanso da praia das $\mathrm{Pi}$ ranhas é um indicador de que esse local é apropriado para a concentração da população reprodutora. Extensas praias de areia encontram-se perto deste remanso. Os comunitários da comunidade de Barroso, que moram perto dessa área, não permitem o uso de redes de arrasto por parte dos pescadores profissionais. Em 1997, a estrutura da população de machos apresentou uma curva normal e a das fêmeas não apresentou qualquer padrão definido. Indivíduos abaixo de $16 \mathrm{~cm}$ de comprimento não foram capturados. Em 1998, o padrão unimodal dos machos adultos se repetiu, aparecendo uma figura similar nas fêmeas, com uma curva desviada para a direita (maior número de indivíduos grandes) (Figura 4D).

No Paraná de Mamirauá, em 1997, capturamos uma grande quantidade de machos e fêmeas, os quais provavelmente deslocavam-se para o rio. A estrutura da população de machos 

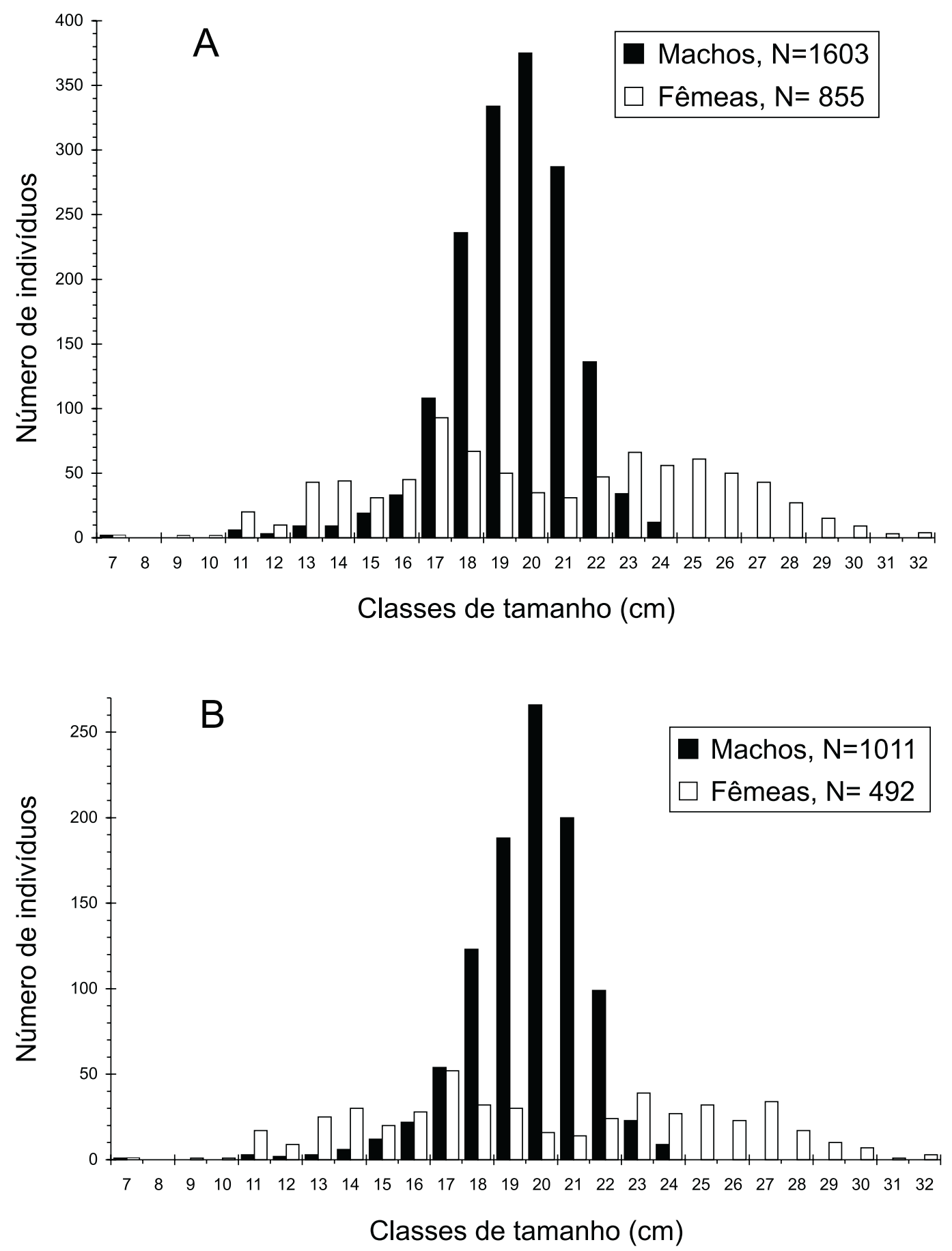

Figura 3 - Distribuição de freqüências de classes de tamanho (comprimento da carapaça) de P. sextuberculata na Área Focal da RDSM (A) e Sistema Hidrológico do Paraná do Jarauá (B). 
Tabela 5 - Porcentagem de machos e fêmeas de $P$. sextuberculata encontrados durante o período de estudo (setembro de 1996 - agosto de 1998) segundo as classes de idade. A, Área Focal da RDSM; B, Sistema Hidrológico do Paraná do Jarauá.

\begin{tabular}{|c|c|c|c|c|c|c|c|}
\hline & \multirow[b]{2}{*}{ IDADE } & \multicolumn{2}{|c|}{$0^{x}$} & \multicolumn{2}{|c|}{ 우 } & \multicolumn{2}{|c|}{ TOTAL } \\
\hline & & $\mathbf{N}$ & $\%$ & $\mathbf{N}$ & $\%$ & $\mathbf{N}$ & $\%$ \\
\hline \multirow[t]{3}{*}{ A } & Juvenis & 45 & 2,8 & 275 & 32,2 & 320 & 13,0 \\
\hline & Subadultos & 108 & 6,7 & 252 & 29,4 & 60 & 14,7 \\
\hline & Adultos & 1450 & 90,5 & 328 & 38,4 & 1778 & 72,3 \\
\hline \multirow[t]{3}{*}{ B } & Juvenis & 16 & 1,6 & 158 & 31,0 & 174 & 11,5 \\
\hline & Subadultos & 76 & 7,5 & 148 & 30,0 & 224 & 14,8 \\
\hline & Adultos & 920 & 90,9 & 192 & 39,0 & 1112 & 73,6 \\
\hline
\end{tabular}

Tabela 6 - Características morfológicas de machos e fêmeas e teste de ANOVA comparando as diferenças entre os sexos de $P$. sextuberculata na RDSM. $\overline{\mathrm{x}}$, média; DP, desvio padrão.

\begin{tabular}{|c|c|c|c|c|c|c|c|}
\hline \multirow[b]{2}{*}{ Característica } & \multicolumn{3}{|c|}{$\sigma^{x}$} & \multicolumn{3}{|c|}{ 우 } & \multirow{2}{*}{$\begin{array}{c}\text { ANOVA } \\
p\end{array}$} \\
\hline & $\overline{\mathbf{x}}$ & DP & $\mathbf{N}$ & $\overline{\mathbf{x}}$ & DP & $\mathbf{N}$ & \\
\hline $\mathrm{CC}(\mathrm{cm})$ & 19,8 & 1,8 & 1603 & 20,7 & 4,9 & 854 & 0,001 \\
\hline Peso (kg) & 0,81 & 0,2 & 1592 & 1,13 & 0,7 & 851 & 0,001 \\
\hline $\mathrm{LC}(\mathrm{cm})$ & 16,0 & 1,2 & 1600 & 17,4 & 4,0 & 853 & 0,001 \\
\hline $\operatorname{ALT}(\mathrm{cm})$ & 6,9 & 0,6 & 1603 & 7,8 & 1,7 & 854 & 0,001 \\
\hline $\mathrm{CP}(\mathrm{cm})$ & 16,5 & 1,4 & 1603 & 17,9 & 4,3 & 854 & 0,001 \\
\hline $\operatorname{LPF}(\mathrm{cm})$ & 3,2 & 0,3 & 1470 & 3,4 & 0,9 & 776 & 0,001 \\
\hline
\end{tabular}

$\mathrm{CC}=$ Comprimento da carapaça, $\mathrm{LC}=$ Largura da carapaça, $\mathrm{ALT}=$ Altura do casco, $\mathrm{CP}=$ Comprimento do plastrão, $\mathrm{LPF}=\mathrm{Largura}$ da placa femoral.

Tabela 7 - Resumo estatístico do comprimento da carapaça de machos e fêmeas de $P$. sextuberculata segundo a idade. $\overline{\mathrm{x}}$, média; DP, desvio padrão.

\begin{tabular}{lcccccc}
\hline & \multicolumn{3}{c}{$\sigma^{\boldsymbol{\top}} \mathbf{( N = 1 6 0 3 )}$} & \multicolumn{3}{c}{ क $\mathbf{( N = 8 5 5 )}$} \\
\hline & Juvenis & Subadultos & Adultos & Juvenis & Subadultos & Adultos \\
\hline $\mathrm{N}$ & 45 & 108 & 1450 & 275 & 252 & 328 \\
$\overline{\mathrm{X}}$ & 14,5 & 18,0 & 20,1 & 16,3 & 19,0 & 25,8 \\
$\mathrm{DP}$ & 2,1 & 1,9 & 1,4 & 2,4 & 3,4 & 2,3 \\
Mínimo & 7,2 & 13,5 & 14,9 & 7,3 & 11,0 & 18,5 \\
Máximo & 17,7 & 22,2 & 24,3 & 21,0 & 25,6 & 32,5 \\
\hline
\end{tabular}


teve a forma de uma curva normal e a das fêmeas, bimodal. A porcentagem de machos juvenis e subadultos foi muito baixa. Em 1998, o número de capturas foi menor e constituído principalmente por juvenis de ambos os sexos. Poucos machos e fêmeas adultas foram capturados (Figura 4E). Aparentemente, as fêmeas de maior tamanho já tinham saído para o rio à procura das praias para realizar a desova, mas há a possibilidade de uma grande extração de indivíduos por parte de pescadores comunitários para serem comercializadas nas cidades de Alvarães e Tefé.

Em dois remansos localizados perto das praias de nidificação no rio Solimões, constatamos que a população havia sido drasticamente dizimada. Na Praia de Machado, capturamos somente dois machos e duas fêmeas adultas (Figura 4F) e, na Praia de Miraflor, nenhuma iaçá foi capturada. Esses dois lugares apresentam excelentes áreas para a nidificação. O Presidente da comunidade de Porto Praia nos comunicou que, em agosto de 1996, houve pesca com rede de arrasto no remanso da Praia de Machado, resultando na captura de 130 iaçás. Não foi feita uma segunda amostragem nesse local porque o remanso do rio havia sido completamente modificado, e o lugar apresentava muita correnteza. $\mathrm{Na}$ Praia de Miraflor, apenas uma fêmea de $P$. sextuberculata e uma fêmea de $P$. unifilis subiram para desovar, e os dois ninhos foram depredados. Em frente a essa praia, de aproximadamente $2 \mathrm{~km}$, moram duas famílias que percorrem continuamente a praia à procura dos ninhos. Soma-se a isso o contínuo trânsito de motores rabeta e recreios em frente dessas áreas de desova e a permanente pesca com redes malhadeiras na ressaca junto à praia.

O remanso da Praia de Horizonte foi amostrado em 1998. Capturamos principalmente machos e fêmeas adultas (Figura 4G). Apesar da captura apresentar um número relativamente baixo de indivíduos, esse remanso é um excelente local para a concentração da população reprodutiva. Na praia, que tem aproximadamen- te $4 \mathrm{~km}$ de extensão, foram registrados $261 \mathrm{ni}$ nhos de iaçá durante a temporada reprodutiva de 1998.

O Lago Mamirauá só foi amostrado em 1997. Encontramos aí uma parte da população que ainda não havia se deslocado para o rio. A maioria era composta por indivíduos com mais de $17 \mathrm{~cm}$ de comprimento. Os machos foram menos freqüentes que as fêmeas. Machos subadultos não foram capturados (Figura $4 \mathrm{H})$.

Em 1998, foi amostrado o Lago Pirarara, capturando-se poucos indivíduos medindo entre 13 e $23 \mathrm{~cm}$ de comprimento. Os machos foram mais freqüentes que as fêmeas. Na estrutura da população, não foi observado nenhum padrão definido, e a população está drasticamente modificada. Machos subadultos não foram capturados (Figura 4I). Nesse lago, são realizadas permanentemente pescarias por parte dos comunitários da reserva e barcos pesqueiros das cidades de Tefé e Alvarães.

Em 1998, amostramos o remanso da Praia de São Francisco de Panauá. Nesse local, apesar de apropriado para a concentração dos indivíduos e do fato existir boas praias para a nidificação, capturamos poucos indivíduos, sendo os machos mais freqüentes que as fêmeas. Não encontramos juvenis e subadultos de ambos sexos. Todos os animais capturados foram machos e fêmeas adultas (Figura 4J). Nesse local, existe uma intensa atividade pesqueira por parte dos comunitários e barcos de pesca de Manaus e Tefé.

O remanso da Praia de Ferro, amostrado em 1998, apresenta praias apropriadas para a nidificação dos quelônios. Nesse local, foram capturados mais machos que fêmeas. Os machos foram mais freqüentes entre as classes de tamanho de 18 e $21 \mathrm{~cm}$ e as fêmeas entre 24 e $31 \mathrm{~cm}$. Não capturamos juvenis e subadultos de ambos sexos. Todos os animais encontrados foram machos e fêmeas adultas (Figura 4K). Nessa praia, a captura de fêmeas e a coleta de ovos são realizadas todos os anos. 
Machos, N=54 $\square$ Fêmeas, N=42

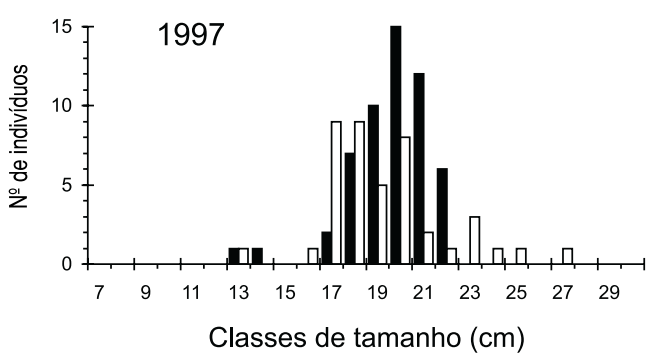

Machos, N=13 $\square$ Fêmeas, N=28

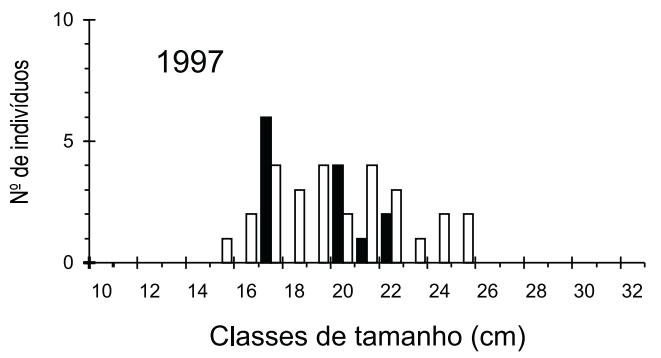

Machos, N=72 $\square$ Fêmeas, N=45

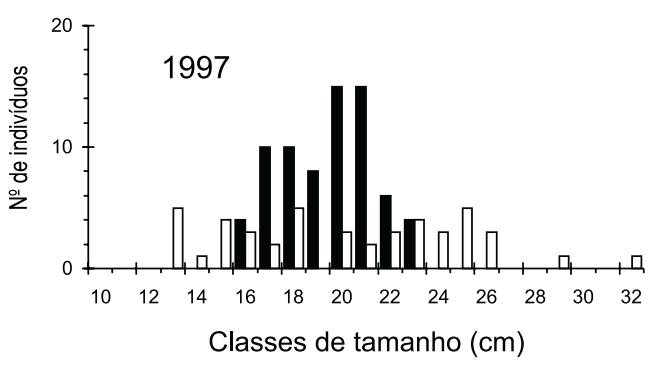

Machos, N=13 $\square$ Fêmeas, N=14

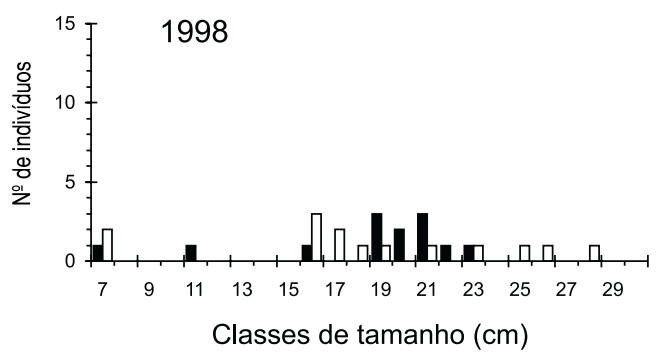

Machos, $\mathrm{N}=4$ Fêmeas, $\mathrm{N}=4$

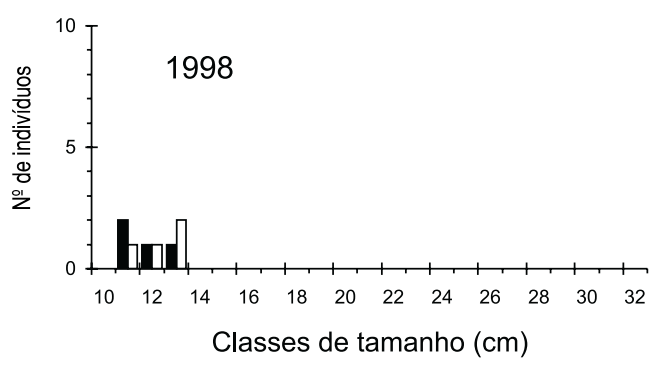

Machos, $\mathrm{N}=12 \square$ Fêmeas, $\mathrm{N}=20$

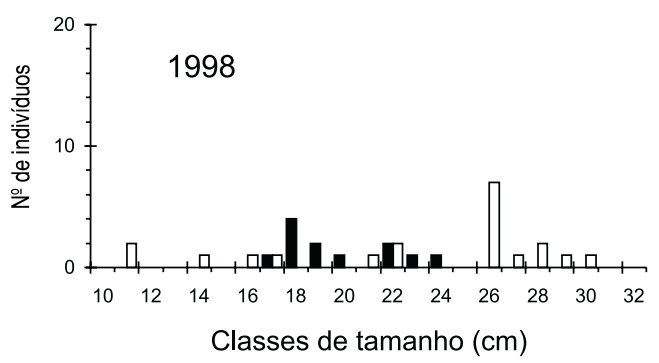

Figura 4 - Distribuição de freqüências de classes de tamanho (comprimento da carapaça) de P. sextuberculata na Área Focal da RDSM. A, Ressaca de Putirí; B, Ressaca de Camarão; C, Lago Jutai. 
Machos, $\mathrm{N}=131 \quad \square$ Fêmeas, $\mathrm{N}=19$

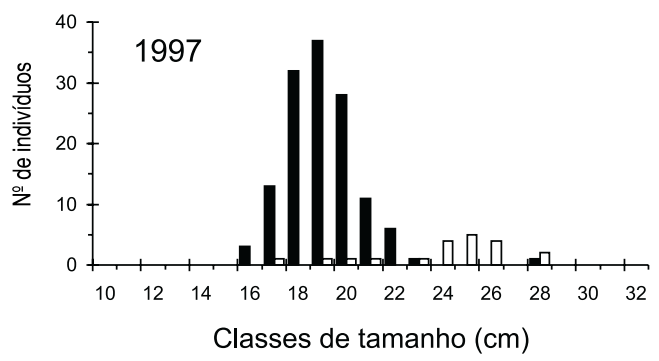

Machos, N=87 $\square$ Fêmeas, N=51

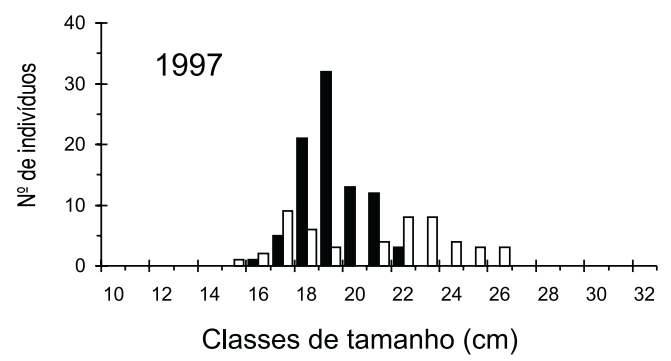

Machos, $\mathrm{N}=2$ Fêmeas, $\mathrm{N}=2$

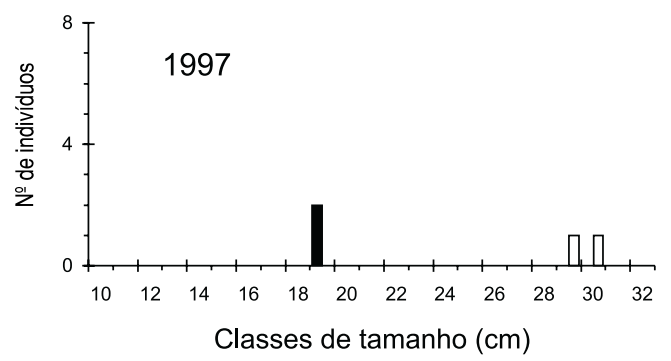

Machos, N=83 $\square$ Fêmeas, N=29

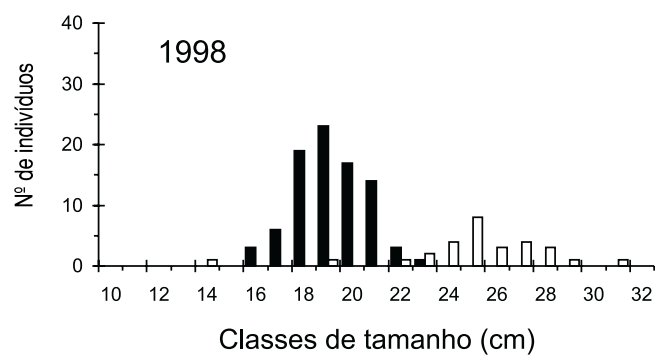

Machos, N=33 $\square$ Fêmeas, N=54

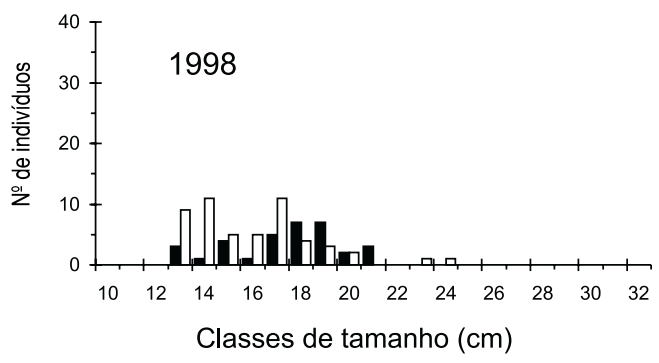

Machos, $\mathrm{N}=16 \quad \square$ Fêmeas, $\mathrm{N}=11$

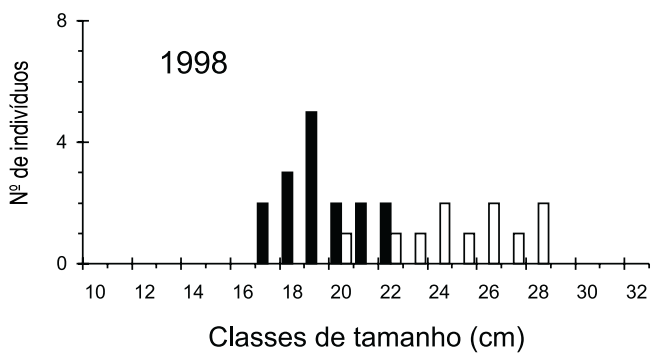

Figura 4 (continuação) - Distribuição de freqüências de classes de tamanho (comprimento da carapaça) de $P$. sextuberculata na Área Focal da RDSM. D, Remanso da Praia das Piranhas; E, Paraná do Mamirauá; F, Remanso da Praia de Machado; G, Remanso da Praia de Horizonte. 

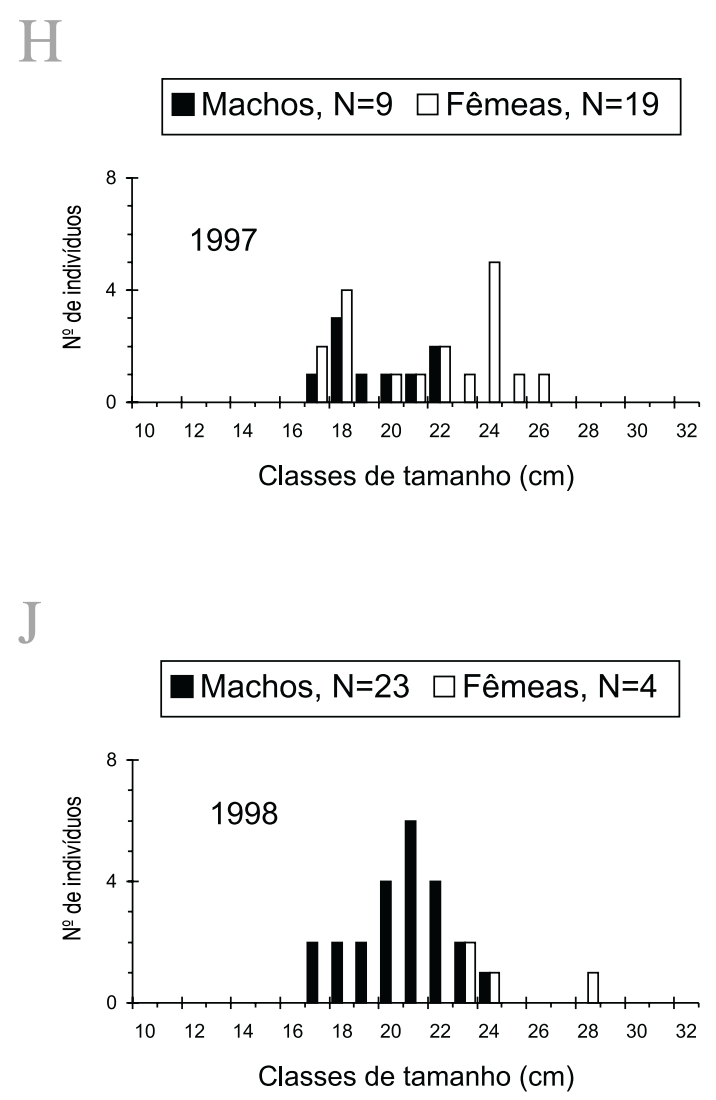
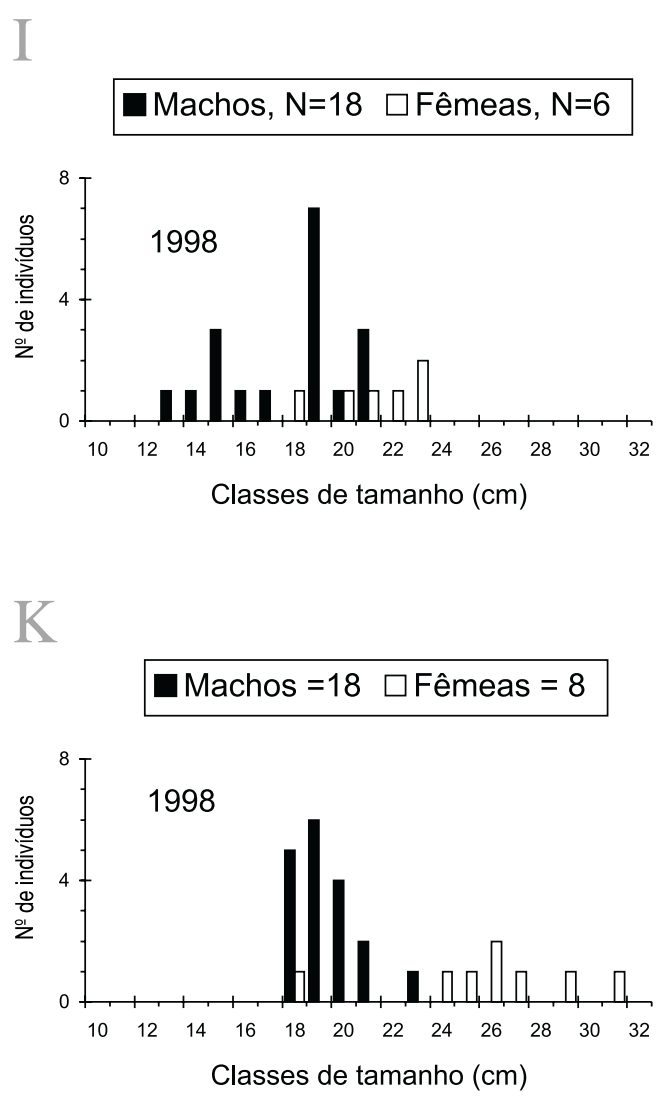

Figura 4 (continuação) - Distribuição de freqüências de classes de tamanho (comprimento da carapaça) de $P$. sextuberculata na Área Focal da RDSM. H, Lago Mamirauá; I, Lago Pirarara; J, Remanso da Praia de São Francisco de Panauá, K, Remanso da Praia do Ferro.

\section{Abundância Relativa Segundo o Local da Amostragem}

A abundância relativa de $P$. sextuberculata variou entre locais de amostragem e anos (Tabela 8, Figura 5). As maiores abundâncias no ano 1997 foram registradas no Paraná de Mamirauá (3,1 animais/hora), remanso da Praia das Piranhas (2,9 animais/hora) e lago Jutai (2,4 animais/hora). Em 1998, esses três locais continuaram sendo os que apresentaram os maiores valores de abundância. Entretanto, quando com- paramos os cinco locais amostrados durante os dois anos consecutivos, observamos uma tendência da diminuição na abundância de iaçás na reserva (Tabela 9). Esse-mesmo resultado foi obtido quando comparamos todos os locais amostrados em 1997 ( $\mathrm{x}=1,7$ animais/hora; $\mathrm{DP}=1,2 ; \mathrm{N}=7)$ e $1998(\mathrm{x}=0,9$ animais/hora; $\mathrm{DP}=0,7 ; \mathrm{N}=9$ ).

\section{Razão Sexual}

A razão sexual, para cada local amostrado 


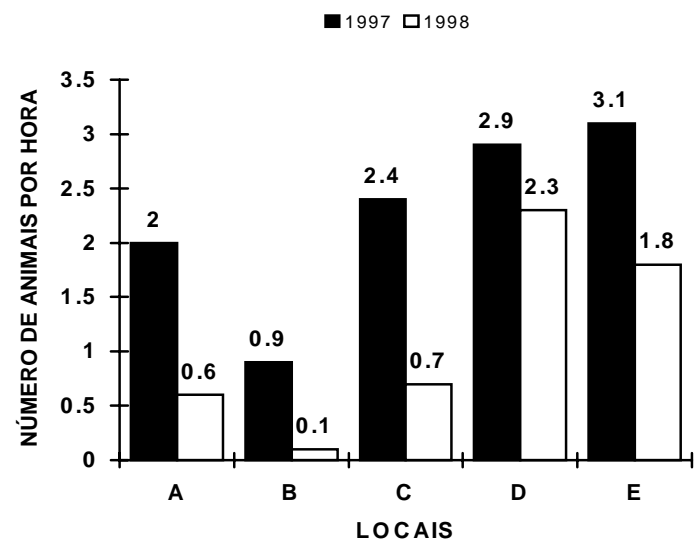

Figura 5 - Número de indivíduos de $P$. sextuberculata capturados por hora, em cinco locais, em torno da Área Focal da RDSM em 1997 e 1998. A, Ressaca de Putiri; B, Ressaca de Camarão; C, Lago Jutai; D, Remanso da Praia das Piranhas; E, Paraná do Mamirauá.

em torno da Área Focal, é apresentada na Tabela 9. A razão sexual baseada em todos os indivíduos da população estudada foi de 1,87: 1 para o total da Área Focal e 2,05:1 para o Sistema Hidrologico do Jarauá.

A razão sexual entre os anos de 1997 e 1998 foi semelhante para a Ressaca de Putiri $\left(\chi^{2}=0,56, \mathrm{df}=1, \mathrm{p}=0,45\right)$ e a Ressaca de Camarão $\left(\chi^{2}=0,99, \mathrm{df}=1, \mathrm{p}=0,32\right)$. A razão sexual entre 1997 e 1998 foi significativamente diferente para o Lago Jutai $\left(\chi^{2}=5,90, \mathrm{df}=1, \mathrm{p}=0,01\right)$, Remanso da Praia das Piranhas $\left(\chi^{2}=7,50, \mathrm{df}=1\right.$, $\mathrm{p}=0,00)$ e Paraná do Mamirauá $\quad\left(\chi^{2}=13,52\right.$, $\mathrm{df}=1, \mathrm{p}=0,00)$. Entretanto, quando comparados todos os locais amostrados em 1997 e 1998, não houve diferenças na razão sexual $\left(\chi^{2}=2,19\right.$, $\mathrm{df}=1, \mathrm{p}=0,13)$.

A razão sexual baseada em adultos que alcançaram a maturidade sexual para toda a Área Focal foi de 4,42:1, desviada para os machos, e para a área de estudo intensivo situada no Sis- tema Hidrológico do Paraná de Jarauá foi de 4,79:1.

\section{Discussão}

\section{Estrutura da População}

Segundo Cagle (1954), um dos atributos da maioria dos répteis é a abundância de indivíduos nos grupos de tamanho pequeno. Gibbons (1968), estudando Emydoidea blandingi, atribuiu a ausência de animais pequenos a diferenças de comportamento entre juvenis e adultos e amostragem seletiva em função do tamanho. Apesar de a população de $P$. sextuberculata na RDSM estar sendo permanentemente explorada pelo homem, em geral, não foi observada uma maior abundância de indivíduos pequenos e uma menor abundância de adultos, como seria esperado. Neste estudo, a ausência desse padrão pode dever-se à alta taxa de perda de ninhos nas praias por predação do homem e mortalidade dos filhotes quando entram na água por predação por diferentes espécies de vertebrados ou, ainda, a preferências de micro-hábitat durante essa fase da vida que não permitiu sua captura com as malhadeiras. Outro fator que deve ser levado em consideração para a ausência desse padrão é o tipo e o tamanho das malhas das redes, que atuaram como forma de seleção do tamanho dos animais capturados.

A ocorrência de curvas bimodais na estrutura da população das fêmeas pode refletir o crescimento mais lento durante essa etapa da vida do animal. O baixo número de fêmeas encontradas pode ser o resultado de predação diferencial pelos comunitários que moram perto das praias e capturam as fêmeas durante a desova.

Em alguns setores da reserva, tais como Mamirauá e Jarauá, os comunitários têm um sistema de proteção de lagos em função do recurso pesqueiro, o que beneficia indiretamente as populações de quelônios. Entretanto, só alguns setores protegem as praias para reprodução desses répteis. 
Tabela 8 - Abundância relativa de P. sextuberculata em diferentes locais da RDSM em 1997 e 1998.

\begin{tabular}{lcc}
\hline & 1997 & 1998 \\
\cline { 2 - 3 } LOCAIS & animais/hora & animais/hora \\
\hline Ressaca de Putiri & 2,0 & 0,6 \\
Ressaca de Camarão & 0,9 & 0,1 \\
Lago Jutai & 2,4 & 0,7 \\
Remanso da Praia das Piranhas & 2,9 & 2,3 \\
Paraná do Mamirauá & 3,1 & 1,8 \\
Remanso da Praia de Machado & 0,1 & - \\
Remanso da Praia de Horizonte & - & 0,6 \\
Lago Mamirauá & 0,6 & - \\
Lago Pirarara & - & 0,5 \\
Remanso da Praia de São Francisco de Panauá & - & 0,6 \\
Remanso da Praia de Ferro & - & 0,5 \\
\hline
\end{tabular}

Tabela 9 - Comparação da razão sexual de $P$. sextuberculata em dois anos consecutivos em torno área focal da RDSM.

\begin{tabular}{|c|c|c|c|c|c|c|c|}
\hline \multirow[b]{3}{*}{ LOCAL } & \multicolumn{4}{|c|}{ Anos e sexo } & \multicolumn{3}{|c|}{ Proporção de sexos } \\
\hline & \multicolumn{2}{|c|}{1997} & \multicolumn{2}{|c|}{1998} & \multirow[t]{2}{*}{1997} & \multirow[t]{2}{*}{1998} & \multirow[t]{2}{*}{$\chi^{2}$} \\
\hline & $\sigma^{\pi}$ & 우 & $\sigma^{x}$ & 우 & & & \\
\hline A. Ressaca de Putirí & 54 & 42 & 13 & 14 & $1,29: 1$ & $0,93: 1$ & NS \\
\hline B. Ressaca de Camarão & 13 & 28 & 4 & 4 & $0,46: 1$ & $1,00: 1$ & NS \\
\hline C. Lago Jutaí & 72 & 45 & 12 & 20 & $1,60: 1$ & $0,60: 1$ & S \\
\hline D. Remanso Praia das Piranhas & 131 & 19 & 83 & 29 & $6,89: 1$ & $2,86: 1$ & $S$ \\
\hline E. Paraná do Mamirauá & 87 & 51 & 33 & 54 & $1,71: 1$ & $0,61: 1$ & $S$ \\
\hline F. Remanso da Praia de Machado & 2 & 2 & & & $1,00: 1$ & & NT \\
\hline G. Remanso da Praia de Horizonte & & & 16 & 11 & & $1,45: 1$ & NT \\
\hline H. Lago Mamirauá & 9 & 19 & & & $0,47: 1$ & & NT \\
\hline I. Lago Pirarara & & & 18 & 6 & & $3,00: 1$ & NT \\
\hline \multicolumn{8}{|l|}{ J. Remanso Praia de São } \\
\hline Francisco de Panauá & & & 23 & 4 & & $5,75: 1$ & NT \\
\hline K. Remanso da Praia do Ferro & & & 18 & 8 & & $2,25: 1$ & NT \\
\hline Todos os locais em torno da Área Focal & 370 & 206 & 220 & 150 & $1,80: 1$ & $1,47: 1$ & NS \\
\hline
\end{tabular}

S = Significativo, NS= Não significativo, NT= Não testado porque apenas uma amostragem foi feita. 
A superexploração de ovos, a captura de adultos e a comercialização de quelônios têm afetado a distribuição de classes de tamanho de $P$. sextuberculata, apesar de a captura comercial ser proibida no Brasil. Essa espécie é protegida pela Legislação Federal de Proteção à Fauna, Lei $\mathrm{N}^{\circ}$ 5.197, embora não exista informação disponível sobre tamanhos populacionais que justifiquem essas medidas.

A escassez ou ausência de adultos em diferentes áreas da RDSM reflete o impacto direto da sobrepesca a que está sendo submetida essa espécie no local estudado. Os resultados encontrados sugerem que a pesca da iaçá com redes malhadeiras para fins comerciais e a captura de fêmeas adultas nas praias podem levar a uma drástica redução da população de fêmeas reprodutivas. É necessário que os comunitários participem da preservação das áreas de nidificação dos quelônios e usem um tamanho de malha adequada nas malhadeiras, fazendo uma coleta seletiva em função do sexo e tamanho dos animais. Apesar dessa prática continuar alterando a razão sexual da população, é, no momento, a única solução até que tenhamos maiores informações sobre a biologia, a ecologia e o comportamento dos sexos, necessárias para se determinar como práticas de manejo poderiam influenciar as populações de $P$. sextuberculata.

Não existem dados sobre a estrutura populacional de $P$. sextuberculata de outros locais para comparação com os dados obtidos neste estudo. A porcentagem de juvenis, subadultos e adultos para ambos os sexos variou muito entre os locais estudados. Isso pode ser o resultado de diferenças na idade de maturação de cada sexo, predação ou comportamento diferencial entre os sexos, ou ainda de fatores ambientais, desviando a população para um sexo durante o período reprodutivo. Para essa espécie, Pezzuti (1998) mostrou que $78 \%$ dos ninhos examinados durante seu estudo na RDSM eram compostos exclusivamente por machos.

\section{Abundância}

Observações preliminares sobre a situação dos quelônios na RDSM indicam que as populações têm declinado drasticamente em função da ação antrópica. Isso é mais evidente em décadas recentes, com o aparecimento e o uso de redes malhadeiras e de redes de arrasto. A coleta de ovos, a captura de fêmeas adultas nas praias e a pesca artesanal e profissional no canal dos rios Solimões e Japurá são os fatores mais importantes do declínio das populações de quelônios.

A abundância de $P$. sextuberculata nesta reserva contrasta com o baixo número de indivíduos de $P$. expansa (1) e $P$. unifilis (4) capturadas ocasionalmente neste estudo. A explicação para essa extrema diferença de abundância é a dificuldade de encontrar indivíduos de $P$. expansa devido principalmente à grande perseguição a que vem sendo submetidos há séculos. $P$. unifilis acha-se mais restrita aos lagos e ressacas, habitando geralmente águas rasas, o que influenciou a captura com as malhadeiras, colocadas em águas mais profundas, um pouco longe da margem. Armadilhas fyke net seriam o melhor método para capturar $P$. unifilis, tal como foi comprovado por Fachín-Terán (1992), durante seu estudo de alimentação numa comunidade de quelônios no rio Guaporé e tributários, no estado de Rondônia, Brasil. Entretanto, o uso de redes malhadeiras e transmalhas em lagos dentro da reserva também deverá ser testado para o estudo desta espécie.

Entre os vegetais que servem de alimento a $P$. sextuberculata, a distribuição e a abundância de espécies da família Poaceae parece ser o mais importante fator influenciando a abundância da espécie. A riqueza de nutrientes nas águas da várzea e a grande produtividade de sementes das Poaceae contribuem para uma maior disponibilidade de recursos alimentares para os quelônios nessa área.

Os quelônios da RDSM estão permanentemente sujeitos à coleta comercial e de subsistência. Três variáveis - densidade populacional, 
proporção de sexos e distribuição de classes de tamanho - foram usadas para comparar a abundância relativa nos locais de amostragem em torno da Área Focal na Reserva Mamirauá. As comparações dos dados de 1997 e 1998 indicam uma diminuição significativa da população de iaçá para todos os locais amostrados duas vezes; porém, faltam dados para explicar essa tendência. O declínio em densidade populacional e distribuição registrado para Sternotherus depressus mostrou-se associado à degradação do hábitat (Bailey e Guyer 1998). Esses autores, com base em estudos de padrões demográficos, concluíram que machos e fêmeas são igualmente afetados por impactos humanos e que a distribuição do tamanho da carapaça está associada com esses impactos. Hidromedusa maximiliani está potencialmente ameaçada pela degradação ambiental de seu único e reduzido hábitat na região da floresta pluvial na Costa Atlântica do Brasil (Souza e Abe 1997).

O ecossistema de várzea na região de Mamirauá tem sido alterado desde o século passado, sendo explorados recursos como madeira, jacarés, quelônios e peixes. Apesar de ser hoje considerada uma reserva, seu estatuto permite o assentamento de comunidades ribeirinhas e o manejo de seus recursos pelos comunitários. Durante a seca, o uso de áreas adjacentes às praias para pastoreio de gado e plantio de culturas de curta duração, tais como melancia, feijão e mandioca, são atividades que afetam o hábitat de reprodução dos quelônios. Atividades recreativas, como natação, campismo e pesca esportiva, têm aumentado durante os últimos anos na reserva, principalmente durante a época da seca, quando emergem as praias, o que favorece essas atividades, pois é permitido o livre trânsito de barcos grandes e pequenos nos dois rios que servem de limites naturais à reserva. Esse fator prejudica principalmente as fêmeas e seus ovos, que são depredados pelo homem.

Em algumas áreas, a população de $P$. sextuberculata está muito alterada devido à superexploração. No rio Solimões, a população de iaçás está muito reduzida. As grandes praias do rio Solimões, que em épocas passadas serviam como locais de desova, está se convertendo em lugares sem vida, passando de grandes incubadoras naturais a gigantescas praias desertas, deixando de cumprir sua importante função biológica. No rio Japurá, a situação é um pouco melhor em função da existência de fiscalização por parte das comunidades, que não permitem o uso de redes malhadeira e redes de arrasto perto das praias de desova. A pesca com redes de deriva é permitida no Japurá, mas espera-se que esta situação mude com a recente criação da Reserva de Desenvolvimento Sustentável Amanã, que protegerá um trecho desse rio.

\section{Razão Sexual}

As características externas usadas para diferenciar machos e fêmeas permitem determinar com certeza o sexo dos indivíduos capturados. Neste estudo, o número de machos de $P$. sextuberculata foi, em geral, maior que o de fêmeas.

A razão sexual de adultos em populações naturais de quelônios varia dentro e entre espécies (Bury 1979). Diferentes estimativas da proporção de cada sexo numa população podem resultar de técnicas de coleta (Gibbons 1970, Vogt 1980), comportamento diferenciado dos sexos, interpretação incorreta da idade ou tamanho na maturidade sexual (Gibbons 1970), ou uma combinação desses fatores. A razão sexual pode ser alterada em espécies em que a determinação do sexo depende da temperatura de incubação dos ovos, em função de diferenças na temperatura de incubação de uma estação para outra (Dodd 1989). Dominância numérica de machos em quelônios adultos já foi registrada, sendo atribuída a desvios de amostragem (Bury 1979), mortalidade diferencial entre os sexos ou diferenças entre os sexos ao atingir a maturidade sexual (Gibbons 1990, Gibbons e Lovich 1990) e temperatura de incubação (Bull e Vogt 1979, Vogt e Bull 1984). Em muitas espécies de quelônios, a razão sexual não difere significativamente de 1:1 (Sternotherus odoratus, Tinkle 1961; Chrysemys picta, Gibbons 1967, 1968, 
Wilbur 1975; Trionyx muticus, Plummer 1977; Graptemuys pseudogeographica e $G$. ouachitensis, Vogt 1980; Emydoidea blandingii, Graham e Doyle 1997; Macroclemys temminckii, Stanley et al. 1998). No Panamá, Moll e Legler (1971) encontraram uma proporção de sexos de 1,9:1 em Pseudemys scripta, atribuindo esse desvio a uma maior mortalidade das fêmeas. Na RDSM, a razão sexual de $P$. sextuberculata foi de 4,42:1. O menor número de fêmeas deveu-se provavelmente à depredação pelo homem, que captura as fêmeas quando sobem às praias para desovar. Esse mesmo fator foi mencionado por Ramo (1982), que encontrou uma proporção de sexos de 2,78:1 em P. vogli. Entretanto, não devemos descartar o fator da idade na maturidade sexual. Segundo Gibbons (1990), em espécies com dimorfismo no tamanho, a razão sexual apresenta-se normalmente desequilibrada em função de que o sexo de menor tamanho atinge a maturidade sexual em uma idade significativamente menor que o sexo de maior tamanho.

A predação diferencial histórica de fêmeas e ninhos resulta na mudança da razão sexual. Ramo (1982) registrou uma razão sexual de 1,45:1 para toda uma população de $P$. vogli da Venezuela, atribuindo o menor número de fêmeas à captura por parte do homem. Fachín-Terán e Vogt (dados não-publicados), trabalhando com $P$. unifilis no rio Guaporé, encontraram, no total da amostra estudada, uma razão sexual desviada a favor dos machos de 8,48:1. Esse desvio pode ser o resultado da influência de fatores ambientais, como baixas temperaturas durante o período crítico de determinação do sexo, o que masculinizaria a população, ou a predação diferencial de fêmeas em nidificação por parte do homem. Para essa mesma espécie, no rio Trombetas (PA), a razão sexual foi de $4: 1$ a favor das fêmeas (Vogt, dados não-publicados). Bataus (1998) registrou uma razão sexual desviada em favor dos machos de 3:1 em $P$. expansa, no rio Crixás-Açu (GO), onde espécimes pequenos não foram coletados. Luiselli (1998) registrou uma razão sexual de 1:1 em
Pelusios castaneus castaneus. Na RDSM, a razão sexual baseada em todos os indivíduos da população de $P$. sextuberculata estudada foi de 1,87:1. As únicas explicações do desvio para os machos são a produção de mais machos que fêmeas nas praias, a ação antrópica e a idade na maturidade sexual. A captura de fêmeas e a coleta de seus ovos são realizadas todos os anos durante a época da seca. Bury (1979) sugeriu precaução ao aceitar razões sexuais diferentes de $1: 1$, principalmente em amostras pequenas, em que, na maioria das vezes a amostragem é seletiva. A amostra deste estudo foi grande, e as capturas foram realizadas com redes de diferentes tamanhos em diferentes hábitats e épocas do ano. Por essa razão, consideramos real a razão sexual encontrada na RDSM.

\section{Agradecimentos}

À Sociedade Civil Mamirauá-SCM, pelo apoio logístico e facilidades concedidas para a realização deste estudo. A Jose Márcio Ayres, por dar-nos a oportunidade de trabalhar na Reserva de Mamirauá. Este estudo foi financiado pela Comunidade Econômica EuropeaCEE, Overseas Development AdministrationODA (hoje DFID) e CNPq/MCT. Augusto Fachín-Terán recebeu uma bolsa de doutorado da CAPES durante sua permanência no Brasil (Departamento de Ecologia do INPA). A Masidonio Pinho de Carvalho, Mariceudo Pinho de Carvalho, Ozimar Neves da Silva, Valdemar Fernandes Martins (Comandante) e Raimundo Nonato Soares Batista pela ajuda e companheirismo indispensáveis durante a coleta de dados. A Miriam Elenit Lima de Fachín e Gabriel William Fachín Lima, pela ajuda na redação em Português. Fazemos uma homenagem ao Biólogo Márcio Ayres, falecido em março de 2003, cujo projeto de vida foi conservar o ecossistema da várzea amazônica e realizar o sonho de um desenvolvimento sustentável para os habitantes da Reserva Mamirauá.

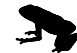




\section{Referências Bibliográficas}

Alho, C. J. R., T. M. S. Danni e L. F. M. Pádua. 1984. Influência da temperatura de incubação na determinação do sexo da tartaruga da Amazônia Podocnemis expansa (Testudinata, Pelomedusidae). Revista Brasileira de Biologia 44: 305-311.

Almeida, S. S., P. G. S. Sá e A. Garcia. 1986. Vegetais consumidos como alimento por Podocnemis (Chelonia) na região de baixo rio Xingu (PA). Boletim do Museu Paraense Emilio Goeldi, Botânica 2: 199-211.

Bailey, K. e C. Guyer. 1998. Demography and population status of the flattened musk turtle, Sternotherus depressus, in the Black Warrior River Basin of Alabama. Chelonian Conservation and Biology 3: 7783.

Bataus, Y. S. L. 1998. Estimativa de parâmetros populacionais de Podocnemis expansa (Tartaruga-daAmazônia) no rio Crixás-Açu (GO) a partir de dados biométricos. Dissertação de Mestrado Não-publicada. Universidade Federal de Goiás, Brasil.

Bull, J. J. e R. C. Vogt. 1979. Temperature-sex determination in turtles. Science 206: 1186-1188.

Bury, R. B. 1979. Population ecology of freshwater turtles. Pp. 571-602 in M. Harless and H. Morlock (eds.), Turtles - perspective and research. New York. John Wiley and Sons.

Cagle, F. R. 1939. A system of marking turtles for future identification. Copeia 1939: 170-173.

Cagle, F. R. 1954. Observation on the life cycles of painted turtles (Genus Chrysemys). The American Midland Naturalist 52: 225-235.

Cantarelli, V. H. e L. C. Herde (eds.). 1989. Projeto quelônios da Amazônia 10 anos. Instituto Brasileiro do Meio Ambiente e dos Recursos Naturais Renováveis. Ministério do Interior, Brasília. 122 pp.

Dodd, C. K., Jr. 1989. Secondary sex ratio variation among populations of the falttened musk turtle, Sternotherus depressus. Copeia 1989: 1041-1045.

Ernst, C. H. e R. W. Barbour. 1989. Turtles of the World. Washington D.C. and London. Smithsonian Institution Press. 313 pp.

Fachín-Terán, A. 1992. Alimentação de cinco espécies de quelônios em Costa Marques, Rondônia - Brasil. Dissertação de Mestrado Não-publicada. Instituto Nacional de Pesquisas da Amazônia/Fundação Universidade do Amazonas, Brasil.

Fachín-Terán, A., A. Acosta e I. Vilchez. 1992. Tortugas Podocnemis mantenidas en cautiverio en los alrededores de Iquitos, Loreto-Perú. Boletín de Lima 84: 79-88.
Fachín-Terán, A., R. C. Vogt e M. F. Gomez. 1995. Food habits of an assemblage of five species of turtles in the Rio Guaporé, Rondônia, Brazil. Journal of Herpetology 29: 536-547.

Fachín-Terán, A., R. C. Vogt e J. B. Thorbjarnarson. 2000. Padrões de caça e uso de quelônios na Reserva de Desenvolvimento Sustentável Mamirauá, Amazonas, Brasil. Pp. 323-337 in E. Cabrera, C. Mercolli e R. Resquin (eds.). Manejo de Fauna Silvestre en Amazonia y Latinoamérica. Asunción.

Gibbons, J. W. 1967. Variation in growth rates in three populations of the painted turtle Chrysemys picta. Herpetologica 23: 296-303.

Gibbons, J. W. 1968. Observations on the ecology and populations dynamics of the Blanding's turlte, Emydoidea blandingi. Canadian Journal of Zoology 46: 288-290.

Gibbons, J. W. 1970. Sex ratio in turtles. Research in Population Ecology 12: 252-254.

Gibbons, J. W. 1990. Sex ratios and their significance among turtle populations. Pp. 171-182 in J. W. Gibbons (ed.). Life History and Ecology of the Slider Turtle. Washington D.C. and London. Smithsonian Institution Press.

Gibbons, J. W. e J. E. Lovich. 1990. Sexual dimorphism in turtles with emphasis on the slider turtle (Trachemys scripta). Herpetological Monographs 4: 1-20.

Graham, T. E. e T. S. Doyle. 1977. Growth and population characteristics of Blanding's turtle Emydoidea blandingii in Massachussetts. Herpetologica 33: 410414.

IUCN. 1996. Red List of Threatened Animals. Compilado e editado por J. Baillie e B. Groombridge. Gland, Switzerland. IUCN. $368 \mathrm{pp}$.

Johns, A. D. 1987. Continuing problems for Amazon river turtles. Oryx 21: 25-28.

Luiselli, L. 1998. Food habitats of the pelomedusid turtle Pelusios castaneus castaneus in southeastern Nigeria. Chelonian Conservation and Biology, 3: 106-107.

Moll, E. O. e J. M. Legler. 1971. The life history of a neotropical slider turtle, Pseudemys scripta (Schoepff). Bulletin of the Los Angeles County Museum of Natural History Science 11: 1-102.

Mrosovsky, N. 1982. Sex ratio bias in hatchling sea turtles from artificially incubated eggs. Biological Conservation 23: 309-314.

Ojasti, J. 1995. Uso y conservación de la fauna silvestre en la Amazonía. Tratado de Cooperación Amazónica, Lima. SPT-TCA 35: 1-216

Páez, V. P. 1995. The conservation and nesting ecology of the endangered yellow-spotted Amazonian river turtle, 
Podocnemis unifilis. Tese de Doutorado Nãopublicada. Athens. Ohio University.

Pezzuti, J. C. B. 1998. Ecologia reprodutiva da iaçá, Podocnemis sextuberculata (Testudines, Pelomedusidae) na RDSM, Amazonas, Brasil. Dissertação de Mestrado Não-publicada. Instituto Nacional de Pesquisas da Amazônia/Fundação Universidade do Amazonas, Brasil.

Plummer, M. V. 1977. Activity habitat and population structure in the turtle, Trionyx muticus. Copeia 1977: 431-440.

Ramo, C. 1982. Biología del galápago (Podocnemis vogli Müller, 1935) en el Hato El Frio, Llanos de Apure, Venezuela. Doñana, Acta Vertebrata 9: 1-161.

SCM. 1996. Mamirauá - plano de manejo. Manaus. IPAAM. Editora Brasilia:CNPq/MTC. 96pp.

Smith, N. J. H. 1979. Aquatic turtles of Amazonia: an endangered resource. Biological Conservation 16: 165-176.

Soini, P. 1995a .Estudio e incubación de los huevos de quelonios acuáticos, 1986. Informe $\mathrm{N}^{\circ}$ 22. Pp. 247-250 in P. Soini, A. Tovar e U. Valdez (eds.), Reporte Pacaya-Samiria. Investigaciones en Cahuana: 19801994. Lima. CDC-UNALM/FPCN/TCN.

Soini, P. 1995b. Estudio y manejo de quelonios acuáticos, 1987. Informe $\mathrm{N}^{\circ}$ 26. Pp. 279-287 in P. Soini, A. Tovar e U. Valdez (eds.), Reporte Pacaya-Samiria. Investigaciones en Cahuana: 1980-1994. Lima. CDCUNALM/FPCN/TCN.

Soini, P. 1997a. Biología y manejo de la tortuga Podocnemis expansa (Testudines, Pelomedusidae). Tratado de Cooperação Amazonica, Caracas, Venezuela, SPT-TCA, $48 \mathrm{pp}$.

Soini, P. 1997b. Ecología y manejo de quelonios acuáticos en la Amazonía Peruana. Pp. 167-173 in T. F. Fang, R. E. Bodmer, R. Aquino e M. H. Valqui (eds.), $M a$ nejo de Fauna Silvestre en la Amazonía. La Paz.

Soini, P. e M. Coppula. 1995. Estudio, reproducción y manejo de los quelonios del género Podocnemis (charapa, cupiso y taricaya) en la cuenca del Pacaya, río Pacaya, Loreto-Perú. Informe $\mathrm{N}^{\circ}$ 2. Pp. 3-30 in $\mathrm{P}$. Soini, A. Tovar e U. Valdez (eds.), Reporte PacayaSamiria. Investigaciones en Cahuana: 1980-1994. Lima. CDC-UNALM/FPCN/TCN.

Soini, P. e M. Soini. 1995a. Ensayos de incubación de huevos de los quelonios del género Podocnemis (charapa, taricaya y cupiso). Informe $\mathrm{N}^{\circ} 12$. Pp. 169-
176 in P. Soini, A. Tovar e U. Valdez (eds.), Reporte Pacaya-Samiria. Investigaciones en Cahuana: 19801994. Lima. CDC-UNALM/FPCN/TCN.

Soini, P. e M. Soini. 1995b. Un resumen comparativo de la ecología reproductiva de los quelonios acuáticos. Informe $\mathrm{N}^{\circ}$ 19. Pp. 215-226 in P. Soini, A. Tovar e U. Valdez (eds.), Reporte Pacaya-Samiria. Investigaciones en Cahuana: 1980-1994. Lima. CDCUNALM/FPCN/TCN.

Souza, R. R. e R. C. Vogt. 1994. Incubation temperature influences sex and hatchling size in the neotropical turtle Podocnemis unifilis. Journal of Herpetology 28: 453-464.

Souza, F. L. e A. S. Abe. 1997. Population structure, activity, and conservation of the neotropical freshwater turtle Hydromedusa maximiliani in Brazil. Chelonian Conservation and Biology 2: 521-525.

Stanley, E. T., J. D. Wilhide e A. Holt. 1998. Population structure and movement patterns of alligator snapping turles (Macroclemys temminckii) in northeastern Arkansas. Chelonian Conservation and Biology 3: 6470 .

Tinkle, D. W. 1961. Geographic variation in reproduction, size, sex ratio and maturity of Sternotherus odoratus. Ecology 42: 68-76.

Vanzolini, P. E. 1977. A brief biometrical note on the reproductive biology of some South American Podocnemis (Testudines, Pelomedusidae). Papeis Avulsos de Zoologia, São Paulo 31: 79-102.

Vanzolini, P. E. and N. Gomes. 1979. A note on the biometry and reproduction of Podocnemis sextuberculata (Testudines: Pelomedusidae). Papeis Avulsos de Zoologia, São Paulo 32: 277-290.

Vogt, R. C. 1980. Natural history of the map turtles Graptemys pseudogeographica and G. ouachitensis in Wisconsin. Tulane Studies in Zoology and Botany 22: 17-48.

Vogt, R. C. 1994. Temperature controlled sex determination as a tool for turtle conservation. Chelonian Conservation and Biology 1: 159-162.

Vogt, R. C. e J. J Bull. 1984. Ecology of hatchling sex ratio in map turtles. Ecology 65: 65-67.

Wilbur, H. M. 1975. The evolutionary and mathematical demography of the turtle Chrysemys picta. Ecology 56: 64-77.

Wilkinson, L. 1990. SYSTAT: The System for Statistics., Evanston, Illinois. SYSTAT Inc. 